\title{
Práticas de medicalização: problematizações conceituais a partir de Michel Foucault
}

\author{
Medicalization practices: conceptual \\ problematizations from Michel Foucault
}

\author{
Flávia Cristina Silveira Lemos ${ }^{1}$ \\ Dolores Cristina Gomes Galindo ${ }^{2}$ (C) \\ Renata Vilela Rodrigues ${ }^{3}$ (1) \\ Ataualpa Maciel Sampaio 4
}

\begin{abstract}
${ }^{1}$ Autora para correspondência. Universidade Federal do Pará (Belém). Pará, Brasil. flaviacslemos@gmail.com ${ }^{2}$ Universidade Federal do Mato Grosso (Cuiabá). Mato Grosso, Brasil. dolorescristinagomesgalindo@gmail.com 3Universidade de Várzea Grande (Várzea Grande). Mato Grosso, Brasil. renatinha.vilela@gmail.com ${ }^{4}$ Hospital Regional do Gama (Brasília). Distrito Federal, Brasil. atau@live.com
\end{abstract}

\begin{abstract}
RESUMO | As práticas de medicalização vêm sendo estudadas por diversos autores e com nuances e perspectivas diferentes, dependendo das análises realizadas e dos autores escolhidos para o campo problemático e conceitual. Pensar práticas em um formato de ensaio teórico é um objetivo deste artigo, formulado em uma vertente dos trabalhos de Michel Foucault e de outros pensadores, os quais pesquisaram e delimitaram os processos de medicalização enquanto objeto de estudo. Portanto, vale mencionar o quanto há polêmicas e paradoxos instalados face às tentativas de apresentar e abordar o presente campo temático de pesquisa a respeito das práticas de medicalização. Neste texto, apresentam-se alguns elementos da medicalização, tais como: a biopolítica; a bioeconomia, o biovalor, as biotecnologias, a farmarcologização, a patologização e a biossociabilidade com o objetivo de forjar uma analítica de poder e saber na sociedade contemporânea, demandando mais trabalhos com vistas à formação uma rede de trabalhos.
\end{abstract}

PALAVRAS-CHAVE: Medicalização. Foucault. Práticas. Biopolítica. Sociedade.

\begin{abstract}
The practices of medicalization have been studied by several authors and with different nuances and perspectives, depending on the analyzes performed and the authors chosen for the problematic and conceptual field. Thinking practices in a theoretical essay format is an objective of this article, formulated in a strand of the works of Michel Foucault and other thinkers, who researched and delimited the processes of medicalization as an object of study. Therefore, it is worth mentioning how much controversy and paradoxes are installed in the face of attempts to present and address the present thematic field of research regarding medicalization practices. In this text, some elements of medicalization are presented, such as: biopolitics; bioeconomics, biovalue, biotechnologies, pharmacologicalization, pathologization and biosociality in order to forge an analytical power and knowledge in contemporary society, demanding more work with training a network of work.
\end{abstract}

KEYWORDS: Medicalization. Foucault. Practices. Biopolitics. Society. 


\section{Introdução}

Este artigo visa problematizar as práticas de medicalização, descrevendo e analisando alguns modos de interrogar este objeto, em um campo de saber e poder, enquanto um diagnóstico do presente, considerando alguns elementos, tais como: biovalor, bioeconomia, biotecnologias, farmacologização, patalogização, biopolítica e biossociabilidade. Há um debate a respeito do conceito de medicalização e inúmeras maneiras de trabalhar com o mesmo.

Neste texto, buscamos contribuições a partir de uma perspectiva de Michel Foucault e outras(os) colegas, os quais possibilitam realizarmos uma analítica dos efeitos das práticas sociais de saber e de poder no que tange aos mecanismos de medicalização. Há um conjunto de maneiras de abordar o conceito de medicalização e de abordar o tempo histórico e os espaços específicos de materialização dos efeitos e modos singulares deste acontecimento se atualizar.

Como diria Deleuze (2008), em Bergsonismo quando deslocamos as perguntas, transformamos as respostas. Com efeito, dependendo da forma de realizarmos a problematização construiremos determinados modos de lidarmos com as práticas delimitadas em linhas de forças, agenciadas em um diagrama. Ou seja, é possível pensar inúmeras racionalidades para a prática medicalizadora, conforme as torções e problematizações feitas a esta prática.

\section{Alguns aspectos iniciais da analítica das práticas de medicalização}

Não medicalizamos somente a doença, fabricando uma patologização, mas também o cotidiano, segundo Foucault (1979) por meio de um processo de medicalização ampliado e indefinido dada a dimensão que alcança no policiamento de cada detalhe da vida (FOUCAULT, 1988). A questão da medicalização dos corpos na modernidade tem-se tornado um tema tão antigo quanto atual na história do pensamento humano. O que hoje parece experimentarmos um cuidado exacerbado pelo corpo, o assunto medicalização dos corpos na sociedade já acontece desde antes das revoluções, no entanto, assumindo formas diversas de enaltecê-lo (DANTAS, 2014).
Sua relevância é justificada por nos remeter a uma profunda análise sobre a existência do homem atual às muitas promessas de felicidade acalantadas e de cura pelo advento da ciência moderna e suas tecnologias através do controle sobre os corpos, seja pelo poder soberano em forma de regulação legal e ordenada por um plano normativo do Direito, concomitantemente pelo poder disciplinar e pela biopolítica, configurando o que Foucault (1999) definiu como biopoder.

Neste sentido, na soberania, pode-se pensar a medicalização juridicamente enquanto acontecimento normativo de uma política de Estado, em nome da defesa social pela promoção, tratamento e garantia do direito à saúde. A lei obriga e proíbe, por exemplo, tomar algumas vacinas para garantir a matrícula na escola e/ou o acesso a uma política social. Neste ponto, a medicalização opera pela soberania jurídica, por meio de uma regulamentação legalista, em formato de um controle da sociedade (FOUCAULT, 1979).

Já, em termos de disciplina, é crucial trabalhar com o campo da emergência do hospital como instituição disciplinar e medicalizada, se materializando pela vigilância da saúde e por dois aspectos: bloqueio dos corpos pela internação e controle minucioso do corpo pelo panóptico (FOUCAULT, 1996). O internamento é um bloqueio para tratamento em saúde e pode ser considerado um dispositivo disciplinar para conter epidemias e cuidar de situações agravadas da saúde. Todavia, a disciplina não é realizada, apenas pela exclusão/internação/segregação, na medida em que pode ser concretizada em meio aberto pelo mecanismo da vigilância generalizada. Um mecanismo é a submissão política e docilidade efetuada pelas ações de saúde mental e coletiva de cunho higienista para prescrever normas de cuidado.

No âmbito da biopolítica, a atuação da medicalização é caracterizada pela gestão da vida em grande escala, inclusive, pela gerência do deixar morrer e do matar em nome da proteção política de grupos supostamente ameaçados por um inimigo construído como risco/perigo para outrem (FOUCAULT, 2008a; 2008b). Nos referimos aqui do governo das condutas da população para impedir/controlar epidemias, gerar dados epidemiológicos e traçar estatísticas para a regulação econômica neoliberal. 


\section{Medicalização e mercado da saúde na (bio)sociedade empresarial}

A noção da medicalização dos corpos como um discurso de "tecnificação da vida", na contemporaneidade, baseada em um saber técnico desponta na ciência enquanto uma crença absoluta, inviolável e inquestionável (DANTAS, 2014). Saberes científicos operam efeitos de cientificismo como regulação cada vez maior sobre a vida da população, os quais vão desde prescrever o que comer, como perder peso, como ter sanidade mental ou não, ou até como adquirir felicidade e sucesso, constituindo o que Ortega (2008) e Rabinow (1999) nomearam de biossociabilidade.

E, em se tratado deste quesito, hoje, ser feliz ou ter uma vida feliz tornou-se um princípio de vida obrigatória pela lógica capitalista. Vida feliz que se resume na busca incessante em adquirir sucesso, status e dinheiro suficientes - mas que nunca chegarão ao patamar da satisfação; e consumo contínuo das novidades lançadas pelo mercado - que são lançadas a todo vapor, longe de poderem parar de consumir. Pois o mercado não somente incita ao consumismo pela satisfação do desejo. Mas para que este desejo se perdure continuamente. Todos os esforços são para que o ciclo seja vicioso e organizar uma biossobilidade enquanto cuidado empresarial, pois, o estilo de vida de alguém se tornou um capital humano, social, político, cultural e relacional (DANTAS, 2014).

Vende-se soluções. Vende-se felicidades. A ideia é mostrar que para todas as dores há um remédio e uma terapêutica a aplicar e a promover com o fim de organizar alguma prática de cuidado constante. Consequentemente, a ideia é cultuar e exaltar os efeitos das medicações. Evidenciando, desta forma a invasão do discurso médico no cotidiano das pessoas. Para aqueles que não alcançarem esta noção de vida feliz, os resta procurar uma solução imediatista e milagrosa, com receio de serem rotuladas, patologizadas ou psicologizadas dentre as várias classificações de doença. Surge neste momento, a figura das indústrias farmacêuticas. Promessas milagrosas, tristeza que vai embora, tumores emocionais que são extraídos: esse é o ápice dessas organizações. A patologização anteriormente instalada por elas mesmas é, agora, milagrosamente suprimida com a simples utilização de algumas cápsulas.
"[...] o medicamento se torna um exemplo precioso do poder da ciência. Do poder de transformar substâncias em poderosos instrumentos de cura. Do poder de reduzir a vida a potentes substâncias. Do poder de transformar o homem em um ser passível de decifração. E, por fim, do poder de se tornar uma verdade sobre os dilemas humanos." (DANTAS, 2014, p. 38).

Mas na história desse uso desenfreado de medicamentos existe uma apropriação do saber-poder da medicina, onde se deu ao discurso médico uma autoridade inviolável sobre o cuidado dos corpos pela prescrição medicamentos. A Farmácia iniciou um debate sobre os usos irracionais e arbitrários de remédios e dos diagnósticos que lhe dão suporte. Um fármaco utilizado de modo excessivo produz iatrogenia, efeitos colaterais nefastos além de gerar muitos problemas de saúde.

Em nome do cuidado, se produz sofrimento e mais doença, em certa medida quando a ausência de ética ganha notoriedade nas tramas da indústria farmacêutica e do mercado da saúde. Portanto, iremos tratar um pouco da história da medicina social pelo Michel Foucault (1986a). Na conferência: “O Nascimento da Medicina Social" (FOUCAULT, 1979), é crucial analisar o quanto os trabalhos de Foucault (1986a) assinalam que a medicalização é uma extensão da medicina sem, porém, a ela se limitar. A medicalização emerge juntamente, no início do século XVIII com o aparecimento da medicina social.

Foi por meio do nascimento da medicina social que o Estado desenvolveu práticas de normalização (na Alemanha), a cidade recebeu práticas higienistas (na França) e o corpo se tornou objeto da força de produção (na Inglaterra). E, ainda hoje, as práticas de medicalização estão fundamentadas pela 1) normalização da conduta separadas pelo binômio normal-anormal em defesa da sociedade; pelas 2) práticas higienistas que utilizam o racismo, o preconceito em nome da ordem social; e 3) pelo empreendedorismo do nosso próprio corpo praticado pelo sistema neoliberal em busca das riquezas e do aumento do consumo, para a permanência da civilização. 
Na Alemanha, a medicina se desenvolveu focada na melhoria da saúde da população, utilizando-se da ciência do Estado - que controlava os corpos em termos de vida e de morte por meio da regulação exercida pelos cartórios -, do saber da estatística para calcular e registrar dados de mortalidade, dados de natalidade, dados de doentes - como se fosse uma polícia médica -, e do saber médico para ter o governo dos corpos e mantê-los saudáveis através da normalização das práticas. "A medicina e o médico são, portanto, o primeiro objeto da normalização. O médico foi o primeiro indivíduo normalizado na Alemanha." (FOUCAULT, 1986a, p. 83).

Enquanto que, na Inglaterra e na França, a medicina estava focada nos trabalhadores pobres e somente no índice de natalidade e mortalidade, preocupada em aumentar a população e atenta em casos de diminuição, sem estar efetivamente preocupada com o desenvolvimento ou melhoria da saúde, diferentemente da Alemanha. (FOUCAULT, 1986a). A segunda etapa da medicina social, dos fins do século XVIII, se desenvolve na França, não como uma medicina estatizada ao máximo, da Alemanha, mas tem um novo fenômeno: a urbanização. Com o amontoamento da população nas cidades, com aumento das epidemias como a peste e a lepra e, consequentemente, aumento do número de mortes, criou-se um "medo urbano". Medo da epidemia, medo da morte, medo do barulho, das oficinas, das indústrias, do aglomerado e grande número de pessoas, dos cemitérios, enfim, "este pânico urbano é característico deste cuidado, desta inquietude político-sanitária que se forma à medida em que se desenvolve o tecido urbano." (FOUCAULT, 1986a, p. 87) Em decorrência desse pânico instalado, em decorrência do perigo iminente tomam-se providências higienistas na medicina urbana. Procura-se tudo que seja considerado nocivo, que provoque doenças, endemias, patogenias em geral, e transfere-se para as periferias da cidade. Portanto, as primeiras providências da medicina urbana não se formaram por uma medicina que analisou privativamente, cada pessoa de forma individual, mas medicina que analisou a população, o tecido social. (FOUCAULT, 1986a).
E veio por último, a força de trabalho como alvo da medicalização. Surgiu no século XIX, na Inglaterra do desenvolvimento industrial, cujo seguimento "pobre" começa a insurgir na sociedade e a preocupar a categoria médica pela ideia de perigo que o pobre causa. Primeiro, porque o pobre tem a capacidade de se revoltar, e segundo, pela epidemia da cólera que atingiu a população proletária. Com a criação da "Lei do Pobres" que tinha por finalidade dar assistência ao proletariado e a plebe, eles recebiam ajuda, mas em contrapartida, eram submetidos a vários controles médicos. Afinal, o socorro tem que servir para algo. Ou o doador dos serviços ou o Estado precisa receber algo em troca. Com essa dinâmica o rico fica protegida da epidemia do pobre e o pobre recebe ajuda gratuita ou com custo baixo do rico. "É uma medicina que é essencialmente um controle da saúde e do corpo das classes mais pobres para torná-las mais aptas ao trabalho e menos perigosas às classes mais ricas." (FOUCAULT, 1986a, p. 97).

Nesse sentido, podemos dizer que a medicina social nada mais é do que o discurso para prevenção de doenças, de rituais de higiene, de preocupação com a saúde. Um cenário que a medicina se aproxima cada vez mais da população para fazer parte do cotidiano das famílias.

Para Foucault (1986a) a medicalização que surgiu com a medicina social tem como elemento nuclear o corpo do indivíduo -poder disciplinar- e o corpo social -biopolítica. Essa nova forma de poder atua sobre os corpos, sobre o cotidiano das pessoas, visando o máximo de docilidade, dentro de um espaço público, controlando o tempo e com sistema de vigilância, produzindo saberes e subjetivando práticas do dia-a-dia. Os indivíduos são causa e efeito do seu saber-poder, continuamente. Poder esse, mais comumente, denominada de medicalização dos corpos. "Penetrar nos corpos de maneira mais detalhada e controlar as populações de modo cada vez mais global. [...] vinculou-se o corpo à sua valorização como objeto de saber e como elemento nas relações de poder." (FOUCAULT, 2015, p. 116-117)

\section{[...] a partir do momento em que passam a ser "coisa" médica ou "medicalizável", como lesão, disfunção ou sintoma, é que vão ser surpreendidas no fundo do organismo ou sobre a superfície da pele ou entre todos os signos do comportamento. (FOUCAULT, 2015, p. 49)}


Qual a relação desses dois poderes com o processo da medicalização? O que é poder disciplinar e o que é bio-política? Quais atravessamentos esses poderes implicam numa totalidade social?

Foucault (1986b) demonstra que esse poder de gerir a vida, inicia por volta do no século XVII e continua no século XVIII, dividindo-o em dois polos: um deles considerou o corpo como máquina; um corpo obediente, adestrado, útil, lucrativo, corpo manipulado e controlado pelos dispositivos econômicos - disciplina do corpo. O corpo do homem máquina reina a docilidade. É um corpo analisável, manipulável. Ele pode ser modificado, deslocado, transformado e aperfeiçoado.

Em outro polo considerou o corpo como espécie; um corpo mais biológico, relacionado mais ao controle da natalidade, da mortalidade, da longevidade e da saúde - regulações da população. Não tem como considerar o poder sobre a vida se o corpo não for estudado a partir desses dois polos. (FOUCAULT 1986b). Já que a medicalização atua através desses dois poderes em toda totalidade do corpo social, o que vem a ser poder? Qual entendimento do em relação ao poder? Foucault (2015, p. 100-101) o poder é:

Como uma multiplicidade de correlações de forças imanentes ao domínio onde se exercem [...] o jogo que, através de lutas e afrontamentos incessantes, as transforma, reforça, inverte; os apoios que tais correlações de forças encontram umas nas outras, formando cadeias ou sistemas, [...] as estratégias em que se originam e cujo esboço geral ou cristalização institucional toma corpo nos aparelhos estatais, na formulação da lei, nas hegemonias sociais. [...] não dever ser procurada na existência primeira de um ponto central, num foco único de soberania.

O poder não se materializa ao nível de um bem que se ganha, se empresta, se troque; mas forças que se locomovem de vários pontos, que atam em malhas, que formam redes, que não tem a função de proibir, e sim, de produzir, que atravessa a totalidade do tecido social. (FOUCAULT, 2015). Sendo assim, para Foucault (2015) o poder anátomo-político do corpo humano que tem o corpo como foco, para adestrar e torná-lo suas habilidades e aptidões mais apuradas para produzir e ser eficaz ao sistema econômico e o poder de intervenções e controles da população - que tem como o foco não só o corpo, mas corpo como espécie; a proliferação dessa espécie; a demografia; a análise estatística dos índices de mortalidade relacionado com os de natalidade, de fecundidade, de longevidade, de saúde e doença; o uso dos saberes da estatística, da medicina, da educação para calcular esses índices; o controle do cotidiano pela escola, pelo exército, pelos hospitais; tudo com intuito de normalizar essa espécie, em nome da segurança e da economia - formam o que Foucault (2015, p.150) denominou de biopoder: "As disciplinas do corpo e as regulações da população constituem os dois polos em torno dos quais se desenvolveu a organização do poder sobre a vida." .

Poder disciplinar + Biopolítica = Biopoder: "[...] técnicas diversas e numerosas para obterem a sujeição dos corpos e o controle das populações. Abre-se, assim, a era de um biopoder. [...]" (FOUCAULT, 2015, p. 151). Um poder essencial para o desenvolvimento do sistema liberal, neoliberal e capitalista, por ajustar os fatores e os índices da população à economia, observado pelo Foucault (2008 p. 389) em Nascimento da Biopolítica que "deve-se governar com a economia, deve-se governar ao lado dos economistas, deve-se governar ouvindo os economistas [...]" (FOUCAULT, 2008, p. 389).

\section{A medicalização como biopolítica e biopoder}

O processo da medicalização, através do poder disciplinar ou da biopolítica gera produção, gera habilidade, gera conhecimento, torna forte as forças de produção e trabalho, consequentemente, melhora a economia, dinamiza o mercado, expande e eleva o ensino. Entretanto, em troca, há um silenciamento das diferenças, há uma invalidação do que é peculiar, do que é único, retira as individualidades. Como também o silencia politicamente, fá-lo diminuir a resistência, o questionamento, a problematização com a finalidade de só produzir e não pensar. (LEMOS, 2014).

Exercer sobre eles uma pressão constante, para que se submetam à subordinação, à docilidade, à atenção nos estudos e nos exercícios, e à exata prática dos deveres e de todas as partes da disciplina. Para que, todos, se pareçam. (FOUCAULT, 1986b, p. 163) 
Silenciar é interditar fala, é filtrar o discurso, é desautorizar quem fala, ou o que fala, ou quando fala; ou que uns falem pelos outros; é impedir a circulação das falas, é excluir enunciados; com a finalidade de fragilizar a resistência, de fracassar a força política, de desestabilizar e desqualificar lutas políticas. (LEMOS, 2014). O poder disciplinar, diferente do poder soberano, onde o centro é o rei centraliza suas ações e intervenções nos corpos dos sujeitos individualizados com a finalidade de adestrá-los e torná-lo obediente aos procedimentos disciplinares para aumentar o potencial produtivo de cada indivíduo, para que ele se aproprie cada vez mais de suas habilidades, torná-lo útil, manipulável para usar, para transformar e para aperfeiçoar, e que se torne rentável e lucrativo ao mercado consumista, e assim, desenvolver a economia, expandir a educação e elevar a moral pública, utilizando-se para isso as instituições de disciplina, como fábrica, escola, prisão, quartel. "A disciplina aumenta as forças do corpo (em termos econômicos de utilidade) e diminuem essas mesmas forças (em termos políticos de obediência)." (FOUCAULT, 1986b, p. 126).

Em segundo lugar, o objeto do controle, cujo exercício é a única cerimônia que importa. Portanto, esses dois métodos - de trabalhar o detalhe e o de exercitar - é que permitem o controle do corpo e imposição da docilidade ao corpo. E é o que ele passa a denominar de disciplinas. Disciplinas estas, tornam-se a fórmula da dominação dos corpos, muito comuns em instituições fechadas como conventos, escolas, exércitos, hospitais, abrigos. No entanto, num contexto diferente do poder soberano sobre os escravos, sobre os empregados, sobre seus feudos; não é um a relação de dominação contínua, um poder de obediência ao trabalho, ao outro, uma verticalização de um sobre o outro. (FOUCAULT, 1986b).

Mas disciplina para Foucault (1986b) é a manipulação que se faz sobre o corpo. Não qualquer manipulação. Manipulação que trabalha nos detalhes do corpo. Recondiciona o corpo não somente a fazer o que se quer, mas como fazer, quando fazer, qual ritmo utilizar, de que forma fazer. Ela cria um corpo disciplinado para ser obediente e dócil aos comandos, mas ao mesmo tempo, ser potente, saudável e incansável.

Ora, se esse poder usa de manobras, de sutilezas, de requinte para manipular o corpo, não tem como ser um poder central, único, de uma só direção, de cima para baixo hierarquizado, de um rei para com seus súditos; mas está em todo lugar, nos centros, nas periferias; em todas as direções, vertical, horizontal; produz e multiplica-se em todo corpo social. É, ao mesmo tempo, um poder que tem eficácia apenas na sua invisibilidade, sendo visível somente nos corpos sujeitados, no que Foucault denominou de sua "forma terminal", para que permanentemente esse poder possa funcionar e manter a sujeição. (FOUCAULT, 1986b)

Silenciam as diferenças, invalidam os aspectos culturais e sociais, retiram a individualidade das pessoas, vidas são anestesiadas, negam o pensar e o problematizar, emudecem os aspectos subjetivos; tudo em nome da ordem social, da paz e da segurança. (LEMOS, 2014) (LEMOS, et al, 2014) Majorar o poder significa redução do custo do poder. A economia do poder é decorrente da diminuição da resistência, da revolta, do descontentamento da população. (FOUCAULT, 2010). A tecnologia do saber médico objetiva criar uma sociedade de controle para padronizar comportamentos, a fim de conquistar seres previsíveis, não resistentes, obedientes, manipuláveis (consumidor). Quanto mais obedientes e dóceis menos questionadores e dissidentes (LEMOS, 2014).

Atendimento mais reforçador de disciplinar e consertar comportamentos não condizentes com os padrões morais da igreja, do mercado, do neoliberalismo, da medicina, das tecnologias, das estéticas. O seu mais importante mecanismo é o da vigilância, não uma vigilância qualquer. Trata-se do Panóptico de Bentham. A partir do panoptismo - um olhar onipresente e um saber onisciente - é possível o controle minucioso dos corpos, é possível intervir no cotidiano das pessoas, domesticar e padronizar comportamentos, produzir corpos dóceis e úteis para a produção e trabalho, com efeitos permanentes.

O indivíduo não é vigiado somente no momento da produção, mas durante todo o trabalho. O poder passa a ser permanente pelo mecanismo da vigilância e controle. Penetra o corpo social na sua totalidade. (FOUCAULT, 2010) Sua habilidade, sua competência, a aplicação dos seus conhecimentos à prática, o ritmo que aplica às atividades, a capacidade de manter equilíbrio emocional, a diligência: tudo é vigiado. "A vigilância torna-se um operador econômico decisivo." (FOUCAULT, 1986b, p. 157). 
Outro dispositivo disciplinar é a sanção normalizadora. Dispositivo que consegue entrar e intervir na escola, na fábrica, no exército, no cotidiano, na família, não somente como práticas punitivas literais de comportamentos contraventores, mas principalmente, condutas que não encaixam no padrão social rentável e produtivo, que não são úteis, corpos que não sejam dóceis e obedientes, indivíduos resistentes, questionadores e críticos. Ao mínimo indício de desvio, é estigmatizado como anormal. (FOUCAULT, 1986b).

A partir da segunda metade do século XVIII o poder disciplinar passa a ser complementado pela biopolítica. Não há uma exclusão do poder disciplinar, ou uma substituição do poder disciplinar pela biopolítica, mas uma adaptação. Ambas intervêm no mesmo espaço, na mesma relação, elas coexistem concomitantemente. (POGREBINSCHI, 2004). Enquanto o poder disciplinar atua diretamente nos corpos dos indivíduos, a biopolítica atua na vida desses indivíduos. Enquanto uma se preocupa em individualizar as pessoas, a biopolítica foca na população, preocupando-se com os índices de natalidade relacionados com os da mortalidade, índices de mortalidade relacionados com os da fecundidade e/ou com a longevidade; índices demográficos por região; índices de epidemia e de endemia. (POGREBINSCHI, 2004).

Foi a vida, muito mais do que o direito, que se tornou objeto das lutas políticas, ainda que estas últimas se formulem através de afirmações de direito. $O$ "direito" à vida, ao corpo, à saúde, à felicidade, à satisfação das

necessidades, o "direito" acima de todas as opressões ou "alienações", de encontrar o que se é e tudo o que se pode ser. (FOUCAULT, 2015, p. 157)

Tanto o poder disciplinar quanto o poder demográfico, tanto o poder de disciplinar a aprendizagem quanto o de controlar a população, tanto o de formar soldados quanto o de regular o corpo foram embasados para ser lançada como a grande tecnologia do poder. (FOUCAULT, 1986b) Fazem uso estratégico de vários saberes como da medicina-psicologizante e psiquiatrizante (pelo diagnóstico da normalidade ou anormalidade), da informática e estatística (pela gestão dos riscos), da farmacologia (pelo uso da medicação), da economia, da epidemiologia, da demografia, do direito. (LEMOS, ET AL, 2014) (LEMOS, 2014) E usam o processo da normalização para "penetrar nos corpos de maneira cada vez mais detalhada ou para controlar as populações de modo cada vez mais global." (FOUCAULT, 2015, p. 116).

\section{Conclusões provisórias}

Com a expansão da ciência biológica, do saber médico, da psiquiatrização, o que poderia ser fonte de vida e de terapia, de resultados fascinantes e de cura, se tornou, na verdade, uma ameaça à vida. As pessoas não se sentem mais competentes em resolver suas próprias adversidades como conflitos, medos, tristezas, dores, ansiedade enfermidades e mortes. Perderam a autonomia da sua própria saúde mental e física e a deslocam aos profissionais da saúde, à ciência médica e aos dispositivos terapêuticos. (DANTAS, 2014). Desde uma simples gripe à perda de um ente passaram a ser tratadas pelas terapias médicas ou medicamentosas disponibilizados em prontuários ou nas prateleiras.

Ao menor impacto de agressão sentida, se recorre aos medicamentos. As pessoas se tornaram dependentes de drogas lícitas, na medida em que criam hábitos pelo uso de medicações e práticas terapêuticas medicinais em qualquer situação intercorrente de suas vidas, em busca de uma resposta instantânea - seja para alívio imediato dos sofrimentos, seja para busca de prazeres, ou para ser feliz. Com o advento da Revolução Industrial e pós lluminismo, a ciência começa a ser vista como capaz de solucionar todas as inquietações do homem, principalmente, após a perda do poder místico da igreja (DANTAS, 2014). Não mais a igreja, mas a ciência passa a produzir a verdade. Não mais a igreja, mas a ciência passa a ter o poder de salvar o homem. Não mais a igreja, mas a ciência passa a ter autoridade sobre a via e a saúde do homem. Não mais a igreja que define o tempo de vida, mas a ciência que prorroga a vida ou desliga a máquina.

Foucault (2015) nos indica que a passagem do saber eclesiástico, bíblico, disseminado pela igreja para o saber científico foi possível pela tecnologia do sexo, em meados do século XVIII. A tecnologia do sexo não mais usa os fundamentos da igreja que era basicamente relacionado à proibição - "quem pratica sexo comete pecado"-, ou decente e moralista permitida apenas aos adultos casados, mas usa saberes da:

Pedagogia, tendo como objetivo a sexualidade específica da criança; o da medicina, com a fisiologia sexual própria das mulheres como objetivo; e, enfim

o da demografia, com o objetivo da regulação espontânea ou planejada dos nascimentos. (FOUCAULT, 2015, p. 126-127). 
A ciência ocupa o lugar anteriormente ocupado por vários outros saberes. A arte, os dogmas da igreja, o cristianismo, as crenças populares, as orientações tradicionais e geracionais, a cultura, o mito estão, cada vez mais, perdendo seu espaço: do poder da fala, do discurso da verdade e da função da moralidade pela ciência. Nem ao menos, o lugar que os feiticeiros ocupavam na sociedade foi poupado, ainda que a sociedade da época tivesse uma confiança pia pelas suas práticas. Hoje, transferida ao saber científico, ao discurso médico. (DANTAS, 2014).

Após o século XX, o avanço da ciência médica se tornou mais acelerada com o advento do cenário tecnológico do discurso médico. Cada vez mais, as indústrias farmacêuticas investem no descobrimento de novas medicações. (DANTAS, 2014). Um aparato tecnológico voltado diretamente em direção ao corpo. Em busca de um corpo disciplinado, saudável, quimicamente transformado e belo. Busca-se o belo porque ser belo é aproximar-se do ideal. Rouanet (2003, p.55) já dizia: “Estamos próximos da realização de uma das mais antigas utopias da humanidade, a utopia médica da saúde perfeita".

O corpo é o palco. Estamos hoje, na cultura do corpo cultuado. Ele está presente nas vitrines, na moda, nas revistas, nas publicidades. Está nos consultórios médicos em busca do imperativo saudável. Está nas cirurgias plásticas, para cultuar o belo. Está nos congressos, para ser objeto permanente de estudo. Ele é a extensão do mercado. (DANTAS, 2014). O corpo saudável e belo é o corpo jovem. Entrar na velhice é ser infeliz. É não ter mais vigor, energia, firmeza. É uma vida entediante. Não é mais lucrativo, útil. Enquanto o jovem é destacado o velho é descartado.

Saúde e estética são indissociáveis e ambos convergem para o mesmo lugar: o corpo. No entanto, a estética refere-se também ao status, ao pertencimento, a inclusão e à aprovação que se terá "na" sociedade e "da" sociedade. Essa cultura de cultuar o corpo e a cultura do consumo desloca a moral puritana para a moral hedonista. Nesse mundo, o espetáculo é a aparência e o consumo, a felicidade. Uma ética e uma estética individualista, ligada apenas ao consumo. $O$ objeto da publicidade tornou-se simbólico. Vende-se tudo, menos o produto anunciado. Com tantas exigências, move-se inclusive o modo como nos comunicamos e nos afirmamos socialmente. (DANTAS, 2014).
Com tantas exigências sofridas para manter este corpo saudável, belo e perfeito, o homem contemporâneo não se sente mais capaz de atendê-lo em todas as suas necessidades. A natureza do corpo não é previsível. Desse corpo é que surgem e propagam o que é inerente e idiossincrático de cada um. Este corpo é que traz marcas, traumas, histórias e cultura. As significações e a existência individual e coletiva são manifestadas pelo corpo. Têm altos e baixos. Para isso, necessita de um suporte técnico a todo o momento. (DANTAS, 2014). Ao se abandonar os possíveis saberes acerca da singularidade, da subjetividade e dos "males" da humanidade na atual modernidade, a ciência, o discurso médico e a psicofarmacologia da contemporaneidade se mostram como a mais perfeita e ideal engenharia do organismo, fundadas na sofisticação tecnológica e no aniquilamento da palavra, do discurso do sujeito e do seu inconsciente.

As pílulas, em embalagens de medicamentos e/ou em outros formatos para o comércio realizado por grupos ávidos por acumulação de capital passaram a ser vendidas como promessa de saúde, de felicidade e de altas performances no trabalho, na escola, na vida sexual, nas instituições punitivas [...] em meio a banalização das prescrições de drogas. (LEMOS, et al, 2014, p. 11)

"As prevenções e tratamentos ganham espaço na política de saúde, enquanto dispositivo que asseguram vida e produção lucrativas." (LEMOS, ET AL, 2016, p. 275) Vendem soluções. Vendem felicidades. A ideia é mostrar que para todas as dores há um remédio. Consequentemente, a ideia é cultuar e exaltar os efeitos das medicações. Evidenciando, desta forma a invasão do discurso médico no cotidiano das pessoas.

"[...] o medicamento se torna um exemplo precioso do poder da ciência. Do poder de transformar substâncias em poderosos instrumentos de cura. Do poder de reduzir a vida a potentes substâncias. Do poder de transformar o homem em um ser passível de decifração. E, por fim, do poder de se tornar uma verdade sobre os dilemas humanos." (DANTAS, 2014, p.38).

De acordo com Dantas (2014), surgem a partir daí, a necessidade desenfreada do uso de fármacos com fins de controlar doenças, manter a saúde, ou ainda, objetivar a cura. Disso, resultam dois fatores: 1) Surgimento das indústrias farmacológicas no Brasil ainda que não tenham tanta expertise para competir 
com o mercado internacional, pela credibilidade adquirida da população brasileira ao que eram produzidas no país, elas se desenvolveram; 2) O hábito da automedicação. Desde aquela época, não era comum ir ao médico para solicitar receituário farmacológico. Comum era a venda de medicação, nas farmácias da época, sem este receituário. As indústrias, aproveitando essa prática brasileira de automedicação, intensificaram a promoção do seu produto em meios de comunicação de maior alcance.

Isso possibilitou a intervenção do saber farmacológico e psiquiátrico em vários aspectos rotulados como fora do padrão da civilização burguesa: mães solteiras, gravidez na adolescência, delinquência infantil e juvenil, aborto não espontâneo, consumo de drogas ilícitas, deficiências neurológicas, transtornos psiquiátricos, pobreza, desemprego; tudo em nome da segurança, do conforto, da paz. (LEMOS, 2014) “Desse modo, a psiquiatria se institui como a defensora da ordem social." (CAPONI, 2009, p. 06).

Um simples ato de indisciplina é diagnosticado como portador de Transtorno de Oposição Desafiadora; um corpo um pouco mais ansioso e inquieto é portador do Transtorno de Déficit de Atenção e Hiperatividade; uma simples tristeza, um choro a mais, é portador de Transtorno de Humor Depressivo; uma simples mania de lavar as mãos é portador de Transtorno Obsessivo Compulsivo; numa lista interminável de comportamentos do cotidiano que são enquadrados como desvios ou fora do padrão da normalidade pelos médicos e indústria farmacêutica prontamente tem a solução para cada um dos desvios (LEMOS, 2014).

A norma [...] é um elemento a partir do qual certo exercício do poder se acha fundado e legitimado. [...] Talvez pudéssemos dizer político. [...] a norma traz consigo ao mesmo tempo um princípio de qualificação e um princípio de correção. A norma não tem por função excluir, rejeitar. Ao contrário, ela está sempre ligada a uma técnica positiva de intervenção e de transformação, a uma espécie de poder normativo.

(FOUCAULT, 2010, p. 43)

Não se pode levar em consideração apenas os saberes biológicos, da psiquiatrização, da patologização, da medicalização. A sociedade biopolítica e a sociedade disciplinar utilizam outros fatores bem mais sutis para subjetivar o indivíduo e a população: através do governo dos riscos e vulnerabilidades e através do potencial produtivo e lucrativo de cada indivíduo.
Castel (1987) em A gestão dos riscos, da anti-psiquiatria à pós-psicanálise, relata como a psiquiatria utilizando o binômio normal e anormal, num movimento racista, higienista e preconceituosa possibilitou a proteção e a segurança do corpo social. Noção de prevenção, de previdência, de antecipação de algum acontecimento desagradável, nasceu da biopolítica, para defesa da sociedade, para a população não ser pega de surpresa.

Para Castel (1987) prevenir é rastrear risco ou fatores de riscos. "[...] uma "mãe de riscos" engendra, ou cria, filhos de riscos." (CASTEL, 1987, p. 125) Prevenir também é vigiar e gerenciar risco. Não vigiar alguém, mas vigiar correlações estatísticas, calcular o indesejável - crimes, delinquência, desvios. Não gerenciar o risco real, mas o provável, uma antecipação de um perigo. Caso o perigo se torne real, caso o indivíduo adoeça, caso o crime aconteça, o Estado entra com a política da medicalização. Caso essa política de medicalização fracasse, o Estado usa a instituição punitiva - encarceramento ou internação. (LEMOS, 2014).

Foucault (2010) em Os Anormais se aproxima desse pensamento do Castel sobre gestão da vida através da segurança, da prevenção do perigo e gestão do risco, pelo distanciamento do crime e da anormalidade. Porque pelas regras da economia do poder de punição se faz necessário trazer a figura do anormal para o crime. Pela gestão do risco, pune-se o criminoso, não o crime. Pune-se o anormal, não a anormalidade. (FOUCAULT, 2010)

Poderíamos chamar de uma patologia da conduta criminosa. [...] serão julgados como criminosos, porém avaliados, apreciados, medidos, em termo de normal e patológico. A questão do ilegal e a questão do anormal, ou ainda, a do criminoso e a do patológico, passam, portanto a ficar ligadas. (FOUCAULT, 2010, p. 78).

A psiquiatria era considerada um ramo da higiene pública, no século XIX. Tinha caráter de limpeza e purificação do tecido social contra todos os perigos que assolasse a sociedade e a pusesse em risco. Foi através dessa concepção de limpeza social contra todas as doenças que a psiquiatria foi institucionalizada como um saber médico. (FOUCAULT, 2010). Para que a teoria médica fosse o mais próximo possível do ramo da higiene social, para que o saber psiquiátrico fosse o encarregado para garantir a higiene social foi preciso que trouxesse a ideia da patologização social - patologizar todos os desvios, os erros, os distúrbios, 
as deficiências - com a função de proteger a sociedade contra esses males. Foi também preciso que a psiquiatria trouxesse a ideia da loucura como perigo, como se os loucos fossem responsáveis pela grande porcentagem do perigo social. Como a psiquiatria era o saber para curar a doença mental, torna-se como único saber legítimo para fazer higiene social dos loucos. Noção de que só ela consegue proteger a sociedade dos loucos, só ela consegue proteger o corpo social do perigo que os loucos acometem, ou que possam cometer. (FOUCAULT, 2010)

Com a junção das duas concepções - loucura como doença e loucura como perigo - durante todo o século XIX e XX, a psiquiatria, consegue trazer um só conceito, um só entendimento: de que a loucura é uma doença e, por isso, é perigosa. Com esse entendimento, não há mais dúvida: a psiquiatria é um saber da teoria médica. Não um saber qualquer, mas um saber único, cuja competência é atuar na higiene social. (FOUCAULT, 2010).

Adquirido a competência de atuar na higiene social através do saber médico, traz cada vez mais a noção do caráter perigoso do louco, a relação do louco com o crime, caracterizando o louco não mais como portador de alucinações, de delírios e de pensamento vago, mas aquele que é contraventor, resistente, desobediente, insubordinado, não dócil, o que se acha um rei, o que não obedece ordens mas as impõem, o que se acha acima de todos. Essa é a atuação da psiquiatria "dentro do manicômio". (FOUCAULT, 2010).

"Fora do manicômio", para Foucault (2010), a psiquiatria traz a noção de que só ela consegue perceber ao mínimo detalhe o perigo que o louco acomete. O saber psiquiátrico traz a noção do risco análogo a um "surto", a um comportamento violento e imprevisível de um doente mental, ou ao perigo, mais leve que seja, o mais sutil e imperceptível que seja aos olhos dos outros, a esse saber, por ser de teoria médica, consegue detectar e impedir que o risco se torne real. O desvio, o anormal, o louco, é um risco à sociedade. E a única intervenção adequada a esses portadores de risco é pelo saber psiquiátrico.
A psiquiatria criou para si mesma esta espécie de sua soberania, do seu poder e do seu saber: eu sou capaz de identificar como doença, de encontrar sinais do que, no entanto, nunca se assinala. [...] diz a psiquiatria - eu sou capaz de reconhecê-la; um crime sem razão, um crime que é, portanto um perigo absoluto, o perigo denso no corpo da sociedade, eu sou capaz de reconhecê-la. Por conseguinte, se posso analisar um crime sem razão, serei rainha. (FOUCAULT, 2010, p. 104).

Através da soberania que adquiriu com a transformação do saber não mais unicamente direcionado aos fatores patológicos tradicionalmente diagnosticados - como delírio, histeria, alucinação - mas um sutil desvio, uma resistência à ordem, um corpo não dócil aos aparelhos político-econômico, se solidificou como um saber apropriado para todos os aspectos do tecido social. Através dessa estratégia, do uso do dispositivo da higiene social, foi possível a expansão da psiquiatria de dentro dos ambientes institucionais. Ela pôde ampliar sua jurisdição e sair de dentro dos manicômios e hospitais, e se infiltrar no mais íntimo aspecto da vida, tornando-se uma psiquiatria ampliada, não mais focada apenas na patologização - direcionada somente à doença - mas no binômio normal e anormal - a anormalidade é muito mais ampla do que os conceitos de doença. (LEMOS, 2014). O movimento higienista ganhou destaque desde a segunda metade do século XIX, e se expande em todo o corpo social através da família e escola. (LEMOS, ET AL, 2014).

Os seguimentos criança, mãe e educadora recebem uma atenção maior da filantropia de cunho médicohigienista pautada em normalizá-las pela orientação e pelo ensino. Esse movimento iniciou com a gestão sobre as pessoas, em especial aos pobres, operacionalizado, na Idade Média, pelas práticas da caridade com dogmas e doutrinas da igreja em nome da salvação das almas sob pena de ir ao inferno; no século XVIII, pela filantropia com atuação de mulheres e beneméritos num viés moralizante de conduta, sob pena de perder os benefícios; e por último, pela filantropia de assistência médico-higienista, utilizando-se de princípios científicos, sob pena de desestruturar famílias e produzir filhos desajustados. (DONZELOT, 1986) 
Enquanto a estratégia da filantropia assistencial funcionou porque direcionou os grandes problemas ameaçadores do século XIX - pauperismo e a reorganização disciplinar das classes trabalhadoras - contra o Estado Liberal, para a esfera privada, por ter criado o discurso sobre a moralidade da poupança não obrigando os operários a depositarem, mas dando a falsa ideia de autonomia (poupança dava uma certa autonomia às famílias); a estratégia da filantropia médico-higienista foi aumentar o número de riscos e perigos da nova tendência industrial para que houvesse uma ciência (ela mesma) com técnicas de prevenção e de combate a esses males. Diante disso, para Donzelot (1986, p. 55-56) nem a filantropia podia ser concebida como,

[...] uma fórmula ingenuamente apolítica de intervenção privada na esfera dos problemas ditos sociais, mas sim uma estratégia deliberadamente despolitizante face à instauração dos equipamentos coletivos, ocupando uma posição nevrálgica equidistante da iniciativa privada e do Estado.

Esse movimento higienista - utilizado pelo liberalismo para assegurar o controle dos modos de vida, controle do comportamento, dos hábitos, da produção, do que expressa através da educação e da saúde tem como foco a medicina, a educação e o Estado para construir uma nação forte, de livre concorrência de mercado transnacional, economicamente e socialmente desenvolvido. O movimento de higiene e prevenção disseminava o saber médico para todo o tecido social, utilizando-se de política racista e preconceituosa em nome da defesa da sociedade. Cartilhas oferecidas nas campanhas educativas contendo técnicas de cuidado e de higiene para ensinar as mulheres e disseminarem conceitos de controle de condutas, higienização social, normalização.

Se obedecer a cartilha contendo técnicas de higiene (de normalização) e o manual de boas condutas (de moralização), terá uma vida saudável, higiênica e longevidade. Terá, ainda, uma família estabilizada, estruturada, uma família "Doriana".

\section{[...] o dispositivo familiar [...] pôde servir de suporte} às grandes "manobras" pelo controle malthusiano da natalidade, pelas incitações populacionais, pela medicalização do sexo e a psiquiatrização de suas formas não genitais. (FOUCAULT, 2015, p. 109)
Esses manuais contêm discursos moralizantes e normalizantes em busca de indivíduos que tenham comportamentos obedientes e padronizados de forma naturalizada. Comportamentos naturalizados produzem dispositivos - utilização de elementos para trazer o desviante ao padrão social, o anormal a ser normal, o dissidente e resistente a ser dócil e obediente. Foucault (1986a, p. 244) conceituou dispositivo como:

[...] um conjunto decididamente heterogêneo que engloba discursos, instituições, organizações, arquitetônicas, decisões regulamentares, leis, medidas administrativas, enunciados científicos, proposições filosóficas, morais e filantrópicas. Em suma, o dito e o não dito são os elementos do dispositivo. $O$ dispositivo é a rede que se pode estabelecer entre esses elementos.

A partir do momento que o ensino se torna obrigatório, frequentar escola se torna uma necessidade maior do que a educação em si. A escola surge tanto para obtenção da paz e da segurança social como para o progresso dessa sociedade. A proposta da escola não é educar. O programa de educação é muito menos de ensino e muito mais político e econômico. Por isso, tem finalidade de formação permanente, pois a sua continuidade assegura o poder político e o econômico. A educação continuada garante desenvolvimento econômico, o crescimento das riquezas, o aumento da produtividade de uma sociedade neoliberal pela expansão dos dispositivos biopolíticos.

A produção de subjetividade é baseada em uma sociedade de controle, a que prescreve formas de ser e de pensar, e não criticar. Isso é que produz a tecnologia do saber médico. Ela objetiva criar uma sociedade que produza comportamentos padrão: comportamentos previsíveis, controlados ou planejados para facilitar a mensuração, o controle e a obediência. As produções científicas não visam à verdade ou ao conhecimento da natureza humana, visa apenas à compreensão dos fenômenos para exercer a previsão e o controle. (DANTAS, 2014).

Na vertente das "Sociedades de Controle", a política é polícia, portanto a vigilância em meio-aberto contínua e modular. Na perspectiva da política de controle social, a democracia é concebida como produção de consenso, a partir da padronização de normas.

(LEMOS, 2008, p. 97) 
Na medicalização dos corpos, o cotidiano da vida, a força empregada no trabalho, na vigilância e no controle da população, os problemas de ordem social, parecem estar se transformando em problema de ordem médica-normalizadora e de ordem neoliberalconsumidora. Não visam apenas a prevenção, a solução de doenças ou a manutenção da saúde. Visam o controle governamental sobre a população com função de regular e disciplinar os indivíduos a seus interesses políticos e econômicos. A biopolítica, pelo Foucault (1999) é "fazer viver e deixar morrer". Ou seja, "regulamenta-se para assegurar e garantir a vida, para prevenir e evitar a morte". (POGREBINSCHI, 2004, p. 197) É um governo de conduta, fomenta o mercado de seguros, nasceu no sistema neoliberal de mercado, tem caráter de investimento e de rendimento, é gerido pelo governo do risco onde tudo passa por cálculos. (RODRIGUES, ET AL, 2015) "O poder tem essencialmente por função proteger, conservar ou reproduzir relações de produção." (FOUCAULT, 2010, p. 43). A máxima do neoliberalismo é fabricar corpos e população que sejam normalizados, padronizados e obedientes com a finalidade de empresariar seu próprio corpo e sua própria vida. (RODRIGUES, ET AL, 2015) “O corpo que produz e consome." (FOUCAULT, 2015, p. 116). Se o adestramento falhar, se a fábrica de corpos falhar, se o processo higienista e o da prevenção falhar, se a gestão do risco e perigo falhar; recorre-se a indústria farmacêutica, a medicalização, a psiquiatrização, a patologização, a psicologização. Se ainda assim falhar, recorre-se a criminalização, a judicialização a utilização de instituições punitivas e penais.

\section{Contribuições das autoras}

Lemos, F. C. S. participou da concepção e escrita. Galindo, D. C. G., Rodrigues, R. V. e Sampaio, A. M. participaram da escrita.

\section{Conflitos de interesses}

Nenhum conflito financeiro, legal ou político envolvendo terceiros (governo, empresas e fundações privadas, etc.) foi declarado para nenhum aspecto do trabalho submetido (incluindo, mas não se limitando a subvenções e financiamentos, participação em conselho consultivo, desenho de estudo, preparação de manuscrito, análise estatística, etc.).

\section{Referências}

Caponi, S. (2009). Biopolítica e medicalização dos anormais. Physis, 19(2), 529-549. Recuperado de https://www. scielo.br/scielo.php?script=sci_abstract\&pid=S010373312009000200016\&lng=en\&nrm=iso\&tlng=pt. doi: 10.1590/S0103-73312009000200016

Carvalho, J. M. (2008). Cidadania no Brasil: o longo caminho (10a ed.). Rio de Janeiro: Civilização Brasileira.

Catel, R. (1987). A Gestão dos Riscos. Da Antipsiquiatria à PósPsicanálise (C. Luz, Trad.). Rio de Janeiro: Francisco Alves.

Catel, R. (1988). As metamorfoses da questão social: uma crônica do salário. Petrópolis: Vozes.

Catel, R. (2011). A Discriminação Negativa: Cidadão ou Autóctones? (2a ed.). Petrópolis, RJ: Vozes.

Castro, E. (2009). Vocabulário de Foucault. Um percurso elos seus temas, conceitos e autores (I. M. Xavier, Trad.). Belo Horizonte: Autêntica.

Cruz, L., Hillesehim, B., \& Guareschi, N.M.F. (2005). Infância e Políticas Públicas: um olhar sobre as práticas psi. Psicologia \& Sociedade, 17(3), 42-49. Recuperado de https://www.scielo.br/scielo.php?pid=S0102$71822005000300006 \&$ script=sci_abstract\&tlng=pt. doi: 10.1590/S0102-71822005000300006

Cruz, L.R. (2006). (Des) articulando as políticas públicas no campo da infância: implicações da abrigagem. Santa Cruz do Sul: Edunisc.

Cruz, L.R., \& Guareschi, N.M.F. (2012). Articulações entre a Psicologia Social e as Políticas Públicas na Assistência Social. In L. R. Cruz, \& N. M. F. Guareschi, (Orgs.). O Psicólogo e as Políticas Públicas de Assistência Social. Petrópolis, RJ: Vozes.

Cruz, L.R., \& Guareschi, N.M.F. (2014). Constituição da Assistência Social como Política Pública: interrogações à psicologia. In L. R. Cruz, \& N. M. F. Guareschi, (Orgs.). Políticas Públicas e Assistência Social (5a ed.). Petrópolis, RJ: Vozes.

Dantas, J. B. (2014). Tecnificação da vida: uma discussão sobre o fenômeno da medicalização na sociedade contemporânea (1a ed.). Curitiba: Crv.

Deleuze, G. (2000). Conversações. São Paulo: Editora 34.

Donzelot, J. (1986). A Polícia das Famílias (2a ed.). Rio de Janeiro: Graal.

Foucault, M. (1986). Microfísica do Poder (6a ed.). Rio de Janeiro: Graal. 
Foucault, M. (1986). Vigiar e Punir (4a ed.) Petrópolis, RJ: Vozes.

Foucault, M. (1999). Em Defesa da Sociedade. São Paulo: Martins Fontes.

Foucault, M. (2008). Nascimento da Biopolítica. São Paulo: Martins Fontes.

Foucault, M. (2010). Os Anormais (2a ed.). São Paulo: Martins Fontes.

Foucault, M. (2015). História da Sexualidade - I: A Vontade do Saber (2a ed.). São Paulo: Paz e Terra.

Lemos, F. C. S. (2012). Práticas de governo das crianças e dos adolescentes propostas pelo UNICEF e pela UNESCO: inquietações a partir das ferramentas analíticas legadas por Foucault. Psicologia \& Sociedade, 24(spe), 52-59. Recuperado de https://www.scielo. br/scielo.php?script=sci_abstract\&pid=S0102$71822012000400009 \&$ Ing=en\&nrm=iso\&tlng=pt. doi: 10.1590/S0102-71822012000400009

Lemos, F. C. S., Cruz, F. F., \& Souza, G. S. (2014). Medicalização da produção da diferença e racismos em algumas práticas educativas pacificadoras. Revista Profissão Docente, 14(30), 7-20. Recuperado de http://www.revistas.uniube.br/index. $\mathrm{php} / \mathrm{rpd} /$ article/view/851

Lemos, F. C. S., Galindo, D. C. G., Santos, C. S., \& Rodrigues, R. D. (2014). UNICEF e algumas práticas de medicalização das famílias e crianças. Revista Polis e Psique, 4(2), 44-64. Recuperado de https://seer.ufrgs.br/PolisePsique/article/ view/49223. doi: $10.22456 / 2238-152 X .49223$

Lemos, F. C. S. (2014). A Medicalização da Educação e da Resistência no Presente: disciplina, biopolítica e segurança. Psicologia Escolar e Educacional, 18(3), 485492. Recuperado de https://www.scielo.br/scielo. php?pid=S1413-85572014000300485\&script=sci abstract\&tlng=pt. doi: 10.1590/2175-3539/2014/0183772

Lemos, F. C. S., Galindo, D. C., \& Vilela, R. (2016) O

Empresariamento Securitário da Vida: O Complexo Tutelar no Mercado Neoliberal da Saúde. Athenea Digital, 16(2), 271-286. Recuperado de https://atheneadigital.net/article/ view/v16-n2-silveira-galindo-vilela. doi: 10.5565/rev/ athenea.1510

Marco, P. S. (1997). Estado, políticas públicas e participação pós Constituição de 1988. Cadernos ABONG, (19).

Pogrebinschi, T. (2004). Foucault, para além do poder disciplinar e do biopoder. Lua Nova: Revista de Cultura e Política, (63), 179-201. Recuperado de https://bit.ly/305ZW80. doi: 10.1590/S0102-64452004000300008 